\title{
Study on the Image of San Diego from the Perspective of English Language and Literature in the Old man and the Sea
}

\author{
Jie $\operatorname{Pan}^{1, a}$ \\ ${ }^{1}$ The Engineering \&Technical College of Chengdu University of Technology, Leshan, Sichuan, \\ 416000 \\ ${ }^{a}$ email
}

Keywords: The Old Man and Sea, English Language and Literature, San Diego

\begin{abstract}
San Diego is a hero of Hemingway's novel "The Old Man and the Sea". Many years of literary commentary have positioned him as a tough guy. This article tries to analyze the character of San Diego in a comprehensive analysis to analyze the other side of San Diego, The characteristics of the image of the Iron and the West, the study of Hemingway in the characterization of characters on the superb artistic expression techniques.
\end{abstract}

\section{Introduction}

Famous American writer Hemingway is good at characterizing the inner world of characters, and to establish the image of personality and vivid characters. His novel "the old man and the sea" on the successful use of a variety of artistic expression techniques, in-depth excavation of the character of the hero San Diego, Li Zhi paper back, into the wood three points to describe the San Diego life of the wind and frost, old, lonely, life is still down Relentless struggle with the fate of the weight of the old fishermen still maintain the image of elegance. Over the years the literary commentary mostly to San Diego as a tough guy image, this article try to San Diego's personality traits a comprehensive analysis, understanding of the other side of the image of San Diego Iron Man - tenderness, hardness and hardness of the image characteristics, so as to experience Hemingway characterization character Characterized by superb artistic expression, literary value and aesthetic value.

\section{San Diego's Unique Image Features}

The novel "The Old Man and the Sea" tells a lonely old Cuban fisherman San Diego is not willing to 84 days without catching the situation of the fish, still full of hope for expeditionary fishing, and finally in the 85th day to catch a large marlin, but in return On the road, unfortunately, by many shark attacks, after hardships, and ultimately outnumbered, Marlins were eaten by sharks only a wreckage. In the novel, Hemingway's San Diego is actually a tender and soft, hard and soft iron. In general, his character has the following aspects: kindness as the father, good friend; into the natural, relentless struggle; unique way of communication, the inner world rich and so delicate.

San Diego's wife has died many years, the novel did not tell whether he had his own children. And most of his exchanges with a boy named Mannuo Lin, from this old and little in the exchanges, we see San Diego as a kindly tenderness. Mannourin began to study fishing with San Diego from the age of five; the old man had a conversation with Mannourin about a baseball game. When Mannorin said he was following the master and never let him take something, San Diego said, "We can It is different "," you are only five years old, I let you take things. " In these conversations, the relationship between the two is also vividly on the paper. San Diego lives alone, life is very tight, the people around from time to time to help the elderly, the elderly always full of gratitude. Mannorin brought someone else to send his beans, rice, fried bananas and stew, San Diego repeatedly said to be grateful, that Mannuo Lin has been thanked, he said, "I want to send him big fish belly where the meat "And when you learned that more than one time was received and taken care of by others, San Diego said," So, apart from the flesh of the belly, I have to send him something else. "He is really thoughtful. Of the words, we see is a friendly San Diego. San Diego's friendliness is not only manifested in the gratitude of others, but also in the sea fishing on birds, fish, 
turtles and the sea and other biological and nature on the deep feelings. On the night of the sea, two five-island whales swam around the boat, and when they heard their tumbling and watering, they said to themselves, "They are all good." He said, "They are just games and They are like our flying fish, and they are our friends. He began to pity the big fish he had caught. The bird that flew to his stern is also pity and love. "How old are you?" "Are you going out for the first time?" "Take a good rest, bird," and "like a man, like a bird, like a fish, to touch your luck." Like a loving father on their own children like, warm and warm. San Diego also said that the big fish is his friend, the stars are his distant friends. Visible, San Diego is a friendly fisherman. Here we see is a Tiehan water tenderness.

Into the natural and natural struggle, which contradictory in San Diego's character to get the perfect unity, which is his "tenderness" Tiehan character of another feature. In the sea, San Diego can rely on the stars, the moon, the wind and so on to determine the weather and hour, with the ocean on the biological situation to determine whether there are fish nearby, all familiar with nature as their old friends as well as his Completely integrated into nature. At this time San Diego and nature is integrated. San Diego went to the sea 84 days nothing, but still adhere to their own ideals and beliefs. Many scenes in the novel depict to us an unyielding image of Tiehan. After the big fish, the sunset, in order to enhance confidence, San Diego will recall their past in the hotel in Casablanca and Hercules match the arm and get the championship thing, in order to cheer yourself. In order to increase the strength, he was eating tuna, but also ready to eat unpalatable loach. "Words back, what is not easy". He is so comforting himself. In the confrontation with the Marlins, he said to the Marlins: "You line, I also line", "I have food", very confident of their own. When the shark constantly attacking the Marlins, San Diego uses harvesters and other tools to drive out and kill the sharks. Finally, San Diego only pulled back a piece of Marlins. San Diego beyond the ordinary people of the Tiehan spirit, making him resist the 84 days of hardships, resistance to the 85th day of the sea when the physical disease problems, ferocious shark attacks. In order to survive, he and all the biological nature of nature must be obtained from the natural, this time he is opposed to nature, and natural things are equal. This is also reflected in the San Diego Iron Man defeated, never to the difficult character, optimism, self-confidence, self-reliance, relentless struggle is his character.

\section{The Role of English Language and Literature}

English language and literature is the English language of the people of the people gathered from the crystallization of wisdom, is the cultural composition of the world an integral part of the culture. Learning English language is not only conducive to reading English works, but also help to improve the reader cultivation. First, learning English language and literature, we must first read the original, to understand the content of literary works, and works behind the social significance, feel the reading experience, broaden their horizons, the establishment of basic English language and literature literacy. Second, to learn the basic knowledge of English language and literature, to understand the history of English language and literature and important literary phenomenon, you can let people feel the diversity of cultural charm, understand the different social development phenomenon, thus open up understanding of the world vision. Third, the study of English language literary works, not only can cultivate sentiment, enrich people's spiritual and cultural life, but also through literary works of life, cultivate a sense of humanistic care and noble aesthetic taste.

\section{Characterization of Character in the Old Man and the Sea}

Thought is the commander of action. Novels written in San Diego many of the body movements, which characterize the characters, reflecting the character played a very good role. San Diego sea fishing when the hook placed to observe the movement of the fishing line, transferred to the big fish after the control rope, control the big fish, resistance to shark attacks and a series of action description, write a sea of experienced fisherman image. We also see a do things bold, action agile, full of wisdom, perseverance of the Iron Man's character starred. In addition, in the novel, the use of stream of consciousness describes the psychological activities of San Diego, depicting the dream of 
San Diego. He has repeatedly dreamed of the lion, but also think of their own past to obtain a strong arm of the championship, then show us a past there have been glorious years of the elderly, but now have to face the hardships of reality, it is very ironic The This approach also put the San Diego Although the face of the situation is still struggling to win the heart of the desire to win, eager to honor, eager to get the respect of the psychological world show at a glance.

The most prominent artistic expression in the novel is the use of symbolic techniques. Symbolic means refers to the abstract thinking into a concrete sense of the kind, abstract as the image, to make it easy for readers to experience the rich heart and dig the role of far-reaching implication. Novels, whether natural or biological, have a profound symbolic significance. The sea symbolizes life, symbolizes society, in the sea, sharks eat turtles, turtles draft, level distinction, the law of the jungle, like the American society at that time. Marlins symbolize the ideals and hopes of life, sharks symbolize the enemy and evil forces, the little boy is a symbol of the disadvantaged groups of helpers. By describing San Diego how to fight the sharks, the full show of San Diego in the face of adversity in the proactive, relentless spirit of struggle. Every time he with the shark when the competition to encourage, question their own words, are tenacious fighting spirit of the best show. San Diego is the representative of the image of Tiehan with the powerful evil forces.

The novel "the old man and the sea" in the San Diego placed on the vast sea, only the vast sea, many of the sea creatures and heaven often change the wind and clouds and San Diego accompanied. This is a set of hope, opportunity and sinister in one environment, to test the unique environment of San Diego, and therefore, San Diego in the sea fighting image is different. Unique background of the environment contrast and rendering so that people appreciate the charm of the tall iron image. Hemingway advocated the simple style of style, and put forward the "iceberg theory" of novel creation. He said: the novel is written on the sea level of one eighth of the things, the sea level under the seven-eighths of the content of the reader needs to understand, to imagine. "The old man and the sea" is the use of "iceberg theory" creation of the model, the novel less than thirty thousand words, the language is also very concise, from the subject of the subjective evaluation and explanation. Content is unusually rich and profound. On the surface, this is just a lonely old fisherman fishing story, the story is extremely simple. But Hemingway to the reader left a very broad imagination. Readers in the enjoyment of San Diego's tenderness, tenacious unyielding charm of the Iron Man, but also deeply think: San Diego is a loser or a winner? Did the fishing operation of San Diego work at the time? Why did San Diego's candle rush for years, but still bear the hardships of hardship and hardships, where is the government and society? What kind of irony does this have? and many more. Hemingway won the Nobel Prize when the award also points out the reasons for his award are: "because he is proficient in modern narrative art, highlighting its recent" old man and the sea ", but also because of his influence on modern style. This award essay speaks the influence and status of Hemingway's "Old Man and the Sea" in the history of American literature and world literature creation. "The application of the theory of iceberg" to Hemingway's "old man and the sea" has a great aesthetic value and literary value, but also the achievements of San Diego became a glorious character in the history of world literature.

\section{Conclusion}

This article through the classic works of Hemingway, the elderly and the hero of the sea image of the image of San Diego, mining the character of the character, to understand the rich and complex inner world, feel a fresh vitality of the old fisherman image. Behind the image of this character is the author of the San Diego old man in the plight of the tenacious struggle of the spirit of appreciation and affirmation, but also the author's own natural feelings of deep feelings. And we appreciate this high literary value of the classic literary works, not only to improve the level of our literary appreciation, cultivate our sentiments, can feel the charm of English language and literature, deepen our English language world culture and values of the knowledge, so that we understand the English language world more than a window. 


\section{References}

[1] Wang Yilin. Analysis of "the old man and the sea" symbolic meaning [J]. Tomorrow fashion, 2017 (02).

[2] Fu Haiyue. "Old man and the sea" character analysis [J]. Young writers, 2017 (14)

[3] Chao Li. A tough guy's desire for love - "The old man and the sea" after reading [J]. Prose hundred, 2017 (01)

[4] Ai Yanhong. On the "old man and the sea" in the complex psychology of the elderly [J]. Read and write, 2008 (01)

[5] Zhang Hairong. "Old man and the sea" tragic implication [J]. Journal of Nantong Vocational College, 2001 (01)

[6] Huang Chunli. "The Old Man and the sea": cultural considerations [J]. Language Teaching and Research, 2012 (36) 